\title{
Opinión
}

\section{Motivado por cirujanos}

\section{(Motivated by Surgeons)}

\author{
Carlos Salazar-Vargas
}

\section{Resumen:}

Comenzaba la década de los 60 y nuestro grupo nerviosamente iniciaba lecciones en los hospitales de San José. En aquellos años, el estudiante de medicina empezaba su contacto con pacientes, por lo menos 1 ó 2 años después de iniciada la carrera. El estudio del ser humano normal que ya habíamos concluido, continuaba con el del enfermo, y más adelante aprenderíamos el tratamiento. La enfermedad descrita en el libro, de pronto se convertía en un enfermo, y es a este a quien hoy veíamos, cohibido pero inquisidor, en la cama de un hospital. Los profesores nos enseñaban a interrogar y a examinar a los pacientes, y cada gesto suyo, cada pregunta, cada maniobra, eran celosamente guardados en la memoria de los educandos. Con claridad percibíamos, aun a temprana edad, las diferencias entre los especialistas, y casi de manera involuntaria, cada quien iba tomando partido y escogía su futuro camino. Fue durante esos tempranos años, cuando mi vida se cruzó con la de 7 maravillosas personas y excelentes cirujanos, que marcaron para siempre mi destino $\mathrm{y}$, sin quererlo ellos, me hicieron inclinarme por la cirugía. Dos eran serios y profundamente académicos: el Dr. Manuel Aguilar Bonilla y el Dr. Vesalio Guzmán Calleja; 3, decididos, incansables y muy hábiles: el Dr. Longino Soto Pacheco, el Dr. Claudio Orlich Carranza y el Dr. Carlos Prada Díaz, y 2, abordables, prácticos, joviales y amistosos: el Dr. Fernando Valverde Soley y el Dr. Randall Ferris Iglesias....

Descriptores: cirujanos, motivación, educación médica

\begin{abstract}
:
During the early 60's our class just started clinical lessons in different hospitals of San Jose. In those years the medical student became in contact with patients 1 or 2 years after initiating his or her career. The study of the normal human being continued with that of the diseased and later on we would learn how to treat our patients.
\end{abstract}

Cirujano, Hospital Dr. Rafael Angel Calderón Guardia.

Correspondencia: carsalva@yahoo.com

ISSN 0001-6002/2010/52/4/255-256

Acta Médica Costarricense, $\mathbb{O} 2010$

Colegio de Médicos y Cirujanos
The disease described in our textbooks, suddenly was a reality, a person lying in a hospital bed, shy but inquisitive. Our teachers taught us how to interrogate and to examine those individuals, and every gesture, every question, every maneuver they did, was jealously kept in our minds. However even at an early stage, we clearly perceived, the differences between medical branches and practitioners, and involuntarily, every one was leaning towards this or that specialty.

It was during those years when 7 wonderful persons and excellent surgeons, crossed the path of my life, inspiring me to follow their steps and to embrace a surgical career. Two were classic academicians, Dr. Manuel Aguilar Bonilla and Dr. Andres Vesalio Guzman Calleja, 3 were determined, tireless and highly skilled, Dr. Longino Soto Pacheco, Dr. Claudio Orlich Carranza, y el Dr. Carlos Prada Diaz, and 2 were, although well prepared, unassuming, practical and openly friendly, Dr. Fernando Valverde Soley y el Dr. Randall Ferris Iglesias. .

Keywords: surgeons, motivation, medical education

Recibido: 14 de mayo de 2010

Aceptado: 10 de agosto de 2010

Comenzaba la década de los 60 y nuestro grupo nerviosamente iniciaba lecciones en los hospitales de San José. En aquellos años, el estudiante de medicina empezaba su contacto con pacientes, por lo menos 1 ó 2 años después de iniciada la carrera.

El estudio del ser humano normal que ya habíamos concluido, continuaba con el del enfermo, y más adelante aprenderíamos el tratamiento. La enfermedad descrita en el libro, de pronto se convertía en un enfermo, y es a este a quien hoy veíamos, cohibido pero inquisidor, en la cama de un hospital.

Los profesores nos enseñaban a interrogar y a examinar a los pacientes, y cada gesto suyo, cada pregunta, cada maniobra, eran celosamente guardados en la memoria de los educandos. Con claridad percibíamos, aun a temprana edad, las diferencias entre los especialistas, y casi de manera involuntaria, cada quien iba tomando partido y escogía su futuro camino. 
Fue durante esos tempranos años, cuando mi vida se cruzó con la de 7 maravillosas personas y excelentes cirujanos, que marcaron para siempre mi destino $\mathrm{y}$, sin quererlo ellos, me hicieron inclinar por la cirugía.

Dos eran serios y profundamente académicos: el Dr. Manuel Aguilar Bonilla y el Dr. Vesalio Guzmán Calleja; 3, decididos, incansables y muy hábiles: el Dr. Longino Soto Pacheco, el Dr. Claudio Orlich Carranza y el Dr. Carlos Prada Díaz, y 2, abordables, prácticos, joviales y amistosos: el Dr. Fernando Valverde Soley y el Dr. Randall Ferris Iglesias.

Los 2 primeros eran imponentes y estaban rodeados de un aura de respeto y de admiración. El Dr. Guzmán vestía una larga gabacha blanca, poseía una mirada fija y penetrante y blandía su índice derecho al hablar. El Dr. Aguilar, a veces de gabacha corta o saco blanco, siempre de hablar bajito, era seguido en la visita por asistentes, residentes, internos y estudiantes, todos en absoluto silencio para no perderle una sola palabra.

Las visitas generales de ambos, ojalá revisando pacientes con enfermedades de la tiroides o del páncreas, eran clases magistrales. Su minuciosidad y sagacidad daban siempre con el diagnóstico evasivo, y su accionar en la sala de operaciones, era un verdadero ejemplo de nitidez y precisión.

Cuando conocí al Dr. Longino Soto, no hacía solo cirugía cardiotorácica, sino también cirugía general compleja.

Aparte de su cargada obligación semanal, los sábados, después de pasar visita en el Hospital Central, hoy Calderón Guardia, se desplazaba al Hospital de Heredia o de Alajuela, en donde le tenían listos otros enfermos para que los interviniera, por supuesto que "por puro amor al arte", puesto que eran instituciones de caridad y la Caja no se había desarrollado.

Las operaciones eran complicadas, los métodos diagnósticos eran muy básicos y los instrumentos rudimentarios, pero los resultados eran buenos.

De hospital a hospital, nos llevaba en su propio carro, y al final del día, después de darnos almuerzo en su casa de El Coyol, nos trasladaba a la parada a tomar el bus a San José, viaje durante el cual mi compañero y yo, no nos cansábamos de repasar y comentar lo que habíamos visto.

El Dr. Claudio Orlich fue siempre preciso y fríamente seguro. Recuerdo una vez cuando teniendo a un ser querido suyo internado y que necesitaba cirugía, me dijo que él mismo lo operaría. Le pregunté con sorpresa, pero con respeto:

-¿Por qué?

Y me dijo:

-¿Cómo no?, ¡si soy el mejor cirujano del país!
Por supuesto que todo le salió bien.

Al finalizar nuestra rotación en su servicio, mi querido compañero, el Dr. Miguel Alfaro, le dijo.

-Dr. Orlich, nosotros estamos muy agradecidos

$\mathrm{Y}$ antes de que pudiera terminar, rápidamente lo interrumpió y le dijo:

-No me agradezcan nada, es obligación mía enseñar.

El Dr. Carlos Prada manejaba un salón enorme, camas ocupadas en toda parte, en los pasillos, en el centro, pacientes hasta en el cuarto de exámenes.

Se presentaba en la mañanita a pasar visita, con las cejas enarcadas, parco en el hablar, directo, de voz firme, a veces temblorosa y fácilmente inflamable, era como una tromba que al pasar deja todo revuelto. Indicaciones médicas, órdenes de exámenes, decisión de operaciones y salidas, todo ocurría rápidamente y luego se iba al quirófano a continuar el frenético trajín. En ocasiones vestía gabacha larga, las más de las veces lucía camisa blanca de manga corta y corbata, y siempre daba la impresión de premura y seriedad.

El Dr. Valverde Soley y el Dr. Ferris eran quizás más jóvenes que los anteriores, eran abiertos, asequibles y sonrientes.

Cualquier esquina, cualquier acera, cualquier sitio alrededor del jardín interno del San Juan, les servían como asiento y aula; la operación más compleja era allí explicada en lenguaje jovial y tono simplista, iy no había manera de no entender!.

Los 2 nos explicaban y conversaban con sencillez, tratándonos de primer nombre, casi como a colegas, nos permitían asistirlos en sus intervenciones y, ocasionalmente, "soltaban" partes de las cirugías, hecho que nos inspiraba.

Ambos también eran compasivos y humildes, al punto de sentarse en la cama de los enfermos para examinarlos o explicarles algo.

Recuerdo que en una oportunidad, durante la visita a un paciente postcolecistectomizado, le mostramos al Dr. Valverde - todos con el ceño fruncido- el apósito empapado en bilis. El enfermo - preocupado- se quedó mirándolo... Y el doctor le dijo:

-iQué lindo color!, ¡dale un par de días y se cierra!.

El señor respiró tranquilo y le agradeció.

Ciencia, abnegación, dedicación, compromiso, respeto, humildad y compasión.

¡Muchas gracias, queridos profesores! ¡Muchas gracias también en nombre de mis pacientes! ¡He tratado de pasar el mensaje!. 